\title{
Giant aneurysm of a major aortopulmonary collateral artery in a 56-year-old woman
}

\author{
Jae Gun Kwak, MD, ${ }^{\mathrm{a}}$ Chang-Ha Lee, MD, ${ }^{\mathrm{a}}$ and Seong Ho Kim, $\mathrm{MD}^{\mathrm{b}}$
}

A 56-year-old Mongolian woman visited our hospital because of dyspnea that had worsened markedly during the previous 2 years. She had been diagnosed with tetralogy of Fallot at 2 years of age, but it had been ignored. When she was 22 years old, she had undergone catheterization in Germany. Her pulmonary vascular bed showed severe hypertensive changes that were considered irreversible with corrective surgery. However, her functional class has been adequate until 2 years before her presentation. Our echocardiographic examination confirmed pulmonary atresia, a large ventricular septal defect (subarterial type, bidirectional shunt), and major aortopulmonary collateral arteries. A huge aneurysm $(>50 \mathrm{~mm}$ in diameter) had originated from 1 of the major aortopulmonary collateral arteries. Initially, we managed her dyspnea with diuretics for 4 months, and her symptoms improved. After 4 months of medical treatment, we evaluated her heart with catheterization. This revealed near-systemic pressure in the right ventricle (164 $\mathrm{mm} \mathrm{Hg}$ vs $180 \mathrm{~mm} \mathrm{Hg}$ in the aorta) and around $80 \%$ oxygen saturation from a systemic artery. We confirmed that her pulmonary vascular bed showed severe hypertensive changes and was inoperable with corrective surgery, ventricular septal defect closure, and unifocalization. Because the giant aneurysm seemed to be at risk of rupture, treatment was needed. We confirmed the exact location of the aneurysm and its relationships with the adjacent structures using computed tomography (Figure 1, $A$ and $B$ ). This giant saccular aneurysm originated from 1 of the major aortopulmonary collateral arteries that originated from the left anterior side of the proximal descending thoracic aorta and supplied the left lung. On the computed tomography scan, it measured around $60 \mathrm{~mm}$ in diameter.

We decided to resect the aneurysm and accessed the lesion by way of a median sternotomy. We dissected the severely adhesive tissues around the aneurysm very carefully. We mobilized the entrance and exit areas of the aneurysm and resected most of it, after clamping the entrance and exit of the vessel (Figure 1, C). Using the remaining aneurysm tissue, we repaired the resected aneurysm (Figure 1,D). In the hope of improving her dyspnea, using a polytetrafluoroethylene (W. L. Gore \& Associates, Inc, Flagstaff, Ariz) vascular graft, we created a central shunt from the ascending aorta to the small main pulmonary artery, which was divided from the right ventricle. She was discharged from the hospital after 2 weeks of general care and arrhythmia management. Her oxygen saturation was around $90 \%$ in the outpatient clinic, and her dyspnea had improved mildly.

\footnotetext{
From the Departments of Thoracic and Cardiovascular Surgery ${ }^{\mathrm{a}}$ and Pediatrics, Sejong General Hospital, Bucheon, Gyeonggi, Republic of Korea.

Disclosures: Authors have nothing to disclose with regard to commercial support.

Received for publication March 5, 2014; accepted for publication March 12, 2014; available ahead of print April 17, 2014.

Address for reprints: Chang-Ha Lee, MD, Department of Thoracic and Cardiovascular Surgery, Sejong General Hospital, 489 St 28, Hohyun-Rho, Sosa-Gu, Bucheon-Si, Gyeonggi-Do 422-711, Republic of Korea (E-mail: leechha@gmail.com).

J Thorac Cardiovasc Surg 2014;148:3242-3

$0022-5223 / \$ 36.00$

Copyright $($ C 2014 by The American Association for Thoracic Surgery

http://dx.doi.org/10.1016/j.jtcvs.2014.03.026
} 


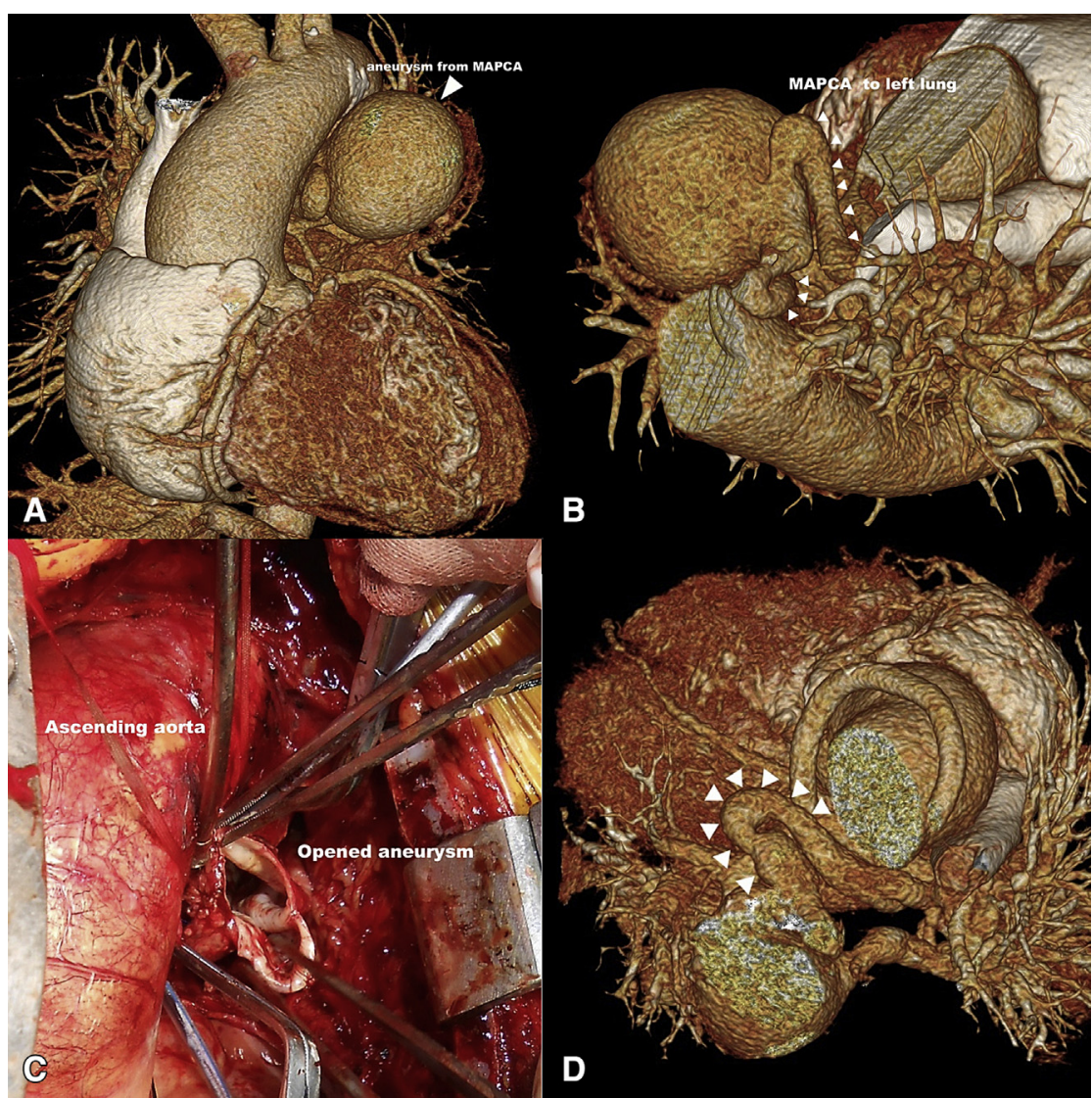

FIGURE 1. A, Anteroposterior view of the 3-dimensional (3D) computed tomography (CT) image. The white triangle indicates the giant aneurysm from a major aortopulmonary collateral artery $(M A P C A)$. B, A right anterior oblique cranial view of the 3D-CT image. The white triangles indicate a MAPCA from the descending aorta to the left lung. C, Operative view of the opened aneurysm from the MAPCA. D, Cranial view of the postoperative 3D-CT image. The white triangles indicate the MAPCA after resection of the aneurysm. 